\title{
REFLEXÕES PRELIMINARES SOBRE A IMPLEMENTAÇÃO DA REFORMA TRABALHISTA NA PARAÍBA E SEUS DESDOBRAMENTOS SOBRE A DINÂMICA DA INFORMALIDADE
}

\author{
José Aderivaldo Silva da Nóbrega \\ Universidade Federal de Campina Grande
}

\begin{abstract}
RESUMO
A Reforma Trabalhista produziu um conjunto de transformações no mercado de trabalho brasileiro entre as quais se incluem novas modalidades de contrato, a redefinição das regras da jornada de trabalho, a modificação nas negociações coletivas, o fim da contribuição sindical compulsória, limitações na atuação da justiça do trabalho entre outros aspectos. A justificativa para isso foi a necessidade de se "modernizar a legislação do trabalho". Há um ano em vigor, as opiniões se dividem em relação aos reais efeitos desta mudança na regulação do trabalho. Afirma-se que os efeitos foram no sentido do retrocesso da proteção social ao mesmo tempo em que se estimulou o crescimento do trabalho informal, o desmonte do sindicalismo e o avanço da precarização e informalização do trabalho. Em face deste cenário em construção, o presente texto tem o objetivo descrever as modificações que já se pode observar nas configurações do trabalho na Paraíba a partir da implementação da reforma. Para levar à frente nosso objetivo analisaremos alguns dados secundários oficiais produzidos pelo IBGE e o MTE, além de outros indicadores gerais. Nossa hipótese é que, no contexto paraibano, tal reforma potencializa o trabalho informal e precário, inclusive, em setores nos quais o nível de formalização e de proteção social eram mais elevados.
\end{abstract}

Palavras-Chave: Mercado de Trabalho. Informalidade. Reforma Trabalhista. Legislação Trabalhista.

\section{PRELIMINARY REFLECTIONS ON THE IMPLEMENTATION OF THE LABOR REFORM IN PARAÍBA AND ITS DEPLOYMENTS ON THE DYNAMICS OF INFORMALITY}

\begin{abstract}
The Labor Reform has produced a series of transformations in the Brazilian labor market, including new contract modalities, redefinition of working day rules, changes in collective bargaining, the termination of compulsory union contribution, limitations in the work labor justice, among other aspects. The justification for this was the need to "modernize labor legislation". A year ago, opinions differ in relation to the real effects of this change in labor regulation. It is said that the effects were towards the retrocession of social protection while stimulating the growth of informal work, the dismantling of trade unionism and the advance of precariousness and informalization of work. In view of this scenario under construction, the present text has the objective to describe the modifications that can already be observed in the configuration of the work in Paraíba from the implementation of the reform. To take forward our objective we will analyze some official secondary data produced by the IBGE and the MTE, in addition to other general indicators. Our hypothesis is that, in the Paraíbaan context, such reform strengthens informal and precarious work, even in sectors where the level of formalization and social protection were higher.
\end{abstract}

Keywords: Labor Market. Informality. Labor Reform. Labor Legislation. 


\section{INTRODUÇÃO}

Em 11 de novembro de 2017 entrou em vigor a Lei $\mathrm{N}^{0} 13.467$ que alterou, em mais de 100 pontos, a Consolidação das Leis Trabalhistas no Brasil. No conjunto de modificações, pode-se dizer que a reforma introduziu novas modalidades de contrato, redefiniu as regras da jornada de trabalho, modificou as negociações coletivas, pôs fim à contribuição sindical, redefiniu as formas de acesso à justiça do trabalho entre outros aspectos. A justificativa para isso foi a necessidade de se modernizar a legislação do trabalho o que, consequentemente, influenciaria a geração de empregos e a retomada do crescimento do país a partir dos investimentos na produção decorrentes desta "maior segurança jurídica".

Há quase dois anos em vigor, as opiniões se dividem em relação aos reais efeitos desta mudança, especialmente, quando se verifica a elevação no número de desempregados para 13,7 milhões, o rebaixamento do salário dos trabalhadores que são readmitidos, o crescimento dos desligamentos por acordos mútuos, portanto, sem a participação dos sindicatos, entre outros aspectos. Na Paraíba, por exemplo, os primeiros indicadores que se tem sobre a implementação da reforma, revelam que o mercado de trabalho no primeiro trimestre de 2018 registrou, em relação ao trimestre anterior, uma queda de $1 \%$ no nível de ocupação e de $2,1 \%$ no trabalho com carteira assinada no setor privado.

Diante do quadro sinalizado acima, o objetivo deste trabalho é descrever as modificações que já se pode observar nas configurações do trabalho na Paraíba a partir da implementação da reforma. Para discutir estas questões, nossa metodologia de trabalho se debruçará na análise de dados secundários oficiais produzidos por IBGE e MTE, além de outros indicadores gerais apontados em pesquisas em curso sobre o mesmo tema. Nossa hipótese é que, no contexto paraibano, tal reforma potencializa o trabalho informal e precário, inclusive, em setores aonde o nível de formalização e de proteção social eram mais elevados.

$\mathrm{O}$ artigo será dividido em três sessões sendo que na primeira apontaremos alguns traços gerais das abordagens contemporâneas da Sociologia a respeito das transformações do mundo do trabalho. Na segunda sessão, descreveremos os pontos mais importantes da reforma e, na terceira, apresentaremos os primeiros dados oficiais que nos mostram os efeitos da reforma trabalhista na Paraíba. 


\section{A MARCHA DA PRECARIZAÇÃO E DA INFORMALIZAÇÃO DO TRABALHO}

Alguns autores que têm se dedicado a refletir a respeito desta última reforma trabalhista no Brasil (Krein et al, 2018; Filgueiras et al, 2018; Santos e Gimenez, 2018) apontam o impacto das mudanças na legislação sobre os processos de precarização, flexibilização e de informalização do trabalho. Manzano e Caldeira (2018), inclusive, apontam, por um lado, um quadro de queda na taxa de informalidade no Brasil de 2012 a 2014 e, por outro lado, uma tendência de elevação a partir do $4^{\mathrm{a}}$ trimestre de 2014 quando salta de 45\% para quase 49\% no ano de 2017 (Manzano e Caldeira, 2018, p. 92). Na argumentação dos autores citados, a reforma consolida as tendências do mercado de trabalho que já vinham se desdobrando desde a crise dos anos 1970 - inclusive no mundo inteiro.

A respeito destes acontecimentos dos anos 1970, na França, por exemplo, houve um período de pleno emprego no período de 1950-1970 que chegou, inclusive, à marca de 85\% de assalariamento. O salário, sob a ótica do fordismo e naquele contexto, não era apenas um pagamento recebido estritamente para atividade executada, mas, para além da remuneração, consistia num status que permitia ao trabalhador acesso a determinados direitos sociais. $\mathrm{O}$ desmantelamento desta sociedade salarial, como denominou Castel (1998), afetava não apenas os trabalhadores desqualificados, marginais, atípicos etc., mas, toda classe trabalhadora uma vez que se tratava de mudanças que estavam no centro da dinâmica capitalista e chegava até aos mais estáveis no conjunto da classe trabalhadora.

Appay e Thébaud-Mony (1997) entendiam que o retrocesso em relação aos direitos sociais conquistados na França decorria, por um lado, das mudanças na estrutura produtiva e da reconfiguração da condição salarial (desemprego em massa, subcontratação, mudanças de estatuto) e, por outro, da transformação da legislação do trabalho que redefine o direito do trabalho e das empresas (Thebaud-Mony e Druck, 2007: 36). Em ambos os casos, o resultado é a institucionalização da insegurança do trabalhador. As saídas para a crise do capital - crise estrutural, segundo Mészáros (2011) - implicaram a redefinição dos vínculos de trabalho e das relações contratuais a ponto de, mesmo entre os trabalhadores os mais estáveis, a instabilidade passaria a ser a norma (Sennet, 2009). Os desdobramentos das mudanças nos processos e nas relações de produção terão desdobramentos diferentes no mundo inteiro, mas, sempre com a tendência a precarização e, de certa maneira, informalização do trabalho.

No caso brasileiro, pode-se dizer que as mudanças na legislação do trabalho visando a flexibilização, as novas condições de negociação do contrato de trabalho com peso no acordo entre patrão e empregado sem passar pela proteção social chegam a ser ainda mais graves uma vez que, sequer, chegamos a uma sociedade salarial (Druck, 2011a) e a formação do mercado de trabalho é 
extremamente desigual se desdobrando de processos de escravidão (Barbosa, 2008; Cardoso, 2010; Souza, 2017), passando por regimes militares com forte repressão às entidades de representação da classe trabalhadora o que fragiliza a referida classe e beneficia os empresários.

Para Alves (2013), a década de 1990 foi cheia de medidas neoliberais que deflagraram a precarização do trabalho e que teve como resultado a nova precariedade salarial na qual a insegurança no empego não diz respeito apenas às categorias do setor privado, mas, também, nas do setor público que perdem benefícios sociais (ALVES, 2013, p. 145). A situação brasileira nos anos 2000 faz Alves (2013) pensar a precarização não apenas como questão salarial, mas, como a precarização do próprio homem-que-trabalha na medida em que corrói a sua vida pessoal e a sua saúde.

A precarização é um problema que afeta os trabalhadores sob muitos aspectos, conforme mostra a literatura nacional e internacional (Druck, 2011; Franco, Druck, Silva, 2010, Alves, 2013, Castel, 1998, Appay, Therbaud-Mony, 2007, Bourdieu, 1998). Ela perpassa a esfera do econômico e tem implicações sociais, políticas, legais, indenitárias, da saúde pública etc. Caminhando lado a lado está a informalidade como outra característica marcante do Brasil e que é potencializada pela medidas de flexibilização e de desregulamentação.

A informalidade, traço marcante no Brasil, é produto, como destacado por Oliveira (2003), da própria dinâmica do capital que se expande no Brasil numa dialética que cria e recria relações de trabalho que são funcionais para o processo de acumulação. Uma das evidências que o autor apresenta é a expansão da indústria automobilística com seu aparato tecnológico e assalariamento padrão, por um lado, e, por outro, a existência das oficinas prestando serviços fora da rede autorizada, e dos "flanelinhas" espalhados pelos semáforos e pontos de parada nas grandes cidades especialmente.

Certas características da reforma trabalhista atual, têm muito a ver com as atividades informais já conhecidas nos anos 1970. Veja, por exemplo, Machado da Silva (1971) que produziu um interessante estudo no qual descreve os mercados de trabalho formal e não formal no Brasil. Embora não use o conceito de informalidade, o autor, lança ideias interessantes sobre a estrutura do mercado brasileiro. Primeiramente, ressalta que ambos se diferenciam, mas, não universos isolados uma vez que fazem parte da dinâmica do mercado de trabalho brasileiro. Ressalta, inclusive, que na divisão do trabalho familiar - no caso estudado das metrópoles brasileiras - há uma combinação entre atividades formais e informais que garante a renda familiar. $\mathrm{Na}$ verdade, as maiores distinções que se pode estabelecer entre ambos os mercados diz respeito ao acesso à proteção social e o reconhecimento legal que configura a atividade formal. 
O ponto interessante deste enfoque é a identificação da importância dos trabalhadores autônomos sem carteira assinada no mercado não formal, bem como a personificação e a flexibilidade das atividades informais que colocam um peso muito forte no indivíduo como gestor de seu próprio trabalho que é uma condição fundamental para que ele possa se estabelecer e ter uma previsão de renda que lhe garanta a reprodução familiar. A flexibilidade do mercado não formal, nos termos de Machado da Silva (1971), diz respeito a jornadas de trabalho muito extensas, em dias e horários variados, bem como tem relação com preços cobrados por serviço prestados ou mercadoria vendida cujos pagamentos, inclusive, são feitos de forma também flexível.

A partir destes apontamentos podemos dizer que, de fato, as regras que definem os tipos de contratos, especialmente, os intermitentes e o autônomo, contribuem para que estas características do mercado de trabalho brasileiro - a precariedade e a informalidade - estejam cada vez mais no centro da dinâmica de acumulação no Brasil. A seguir levantamos alguns pontos para se pensar esta marcha em curso.

\section{OS TRAÇOS DA REFORMA TRABALHISTA APROVADA}

A reforma trabalhista tem sido vendida como uma forma de "modernizar" as relações trabalhistas e garantir maior competitividade das empresas brasileiras na medida em que poderia haver mais investimentos em razão do rebaixamento dos custos do trabalho e desburocratização. José Pastore, um dos principais autores tomados por referência para elaboração do Parecer do PL 6787/16 que subsidiou a formulação da reforma, chegou a afirmar que a "espinha dorsal" da nova legislação seria a "valorização da negociação coletiva" que garante que empregados e empregadores possam "estabelecer proteções de forma diferente do que prega a CLT, sem revogar naquela lei os direitos agora negociáveis" (PASTORE, 2017, S/P).

$\mathrm{Na}$ interpretação de Pastore, a reforma não revoga a CLT, mas, dá condições de sair do engessamento e mais "liberdade às partes" para negociarem sob outros termos que não aqueles da Lei. Tal negociação, na sua argumentação, tem limitações porque no próprio PLC define-se uma série de direitos que são inegociáveis por se tratar das seguintes cláusulas constitucionais: "proteções da saúde, licenças-maternidade e paternidade, aviso prévio, seguro contra acidentes e vários outros que, no projeto em tela, são tratados como cláusulas pétreas" (PASTORE, 2017, S/P). Ainda sob o olhar por dentro da defesa da reforma, a negociação possível se refere à jornada de trabalho, parcelamento das férias, trabalho por produtividade, teletrabalho, tempo de descanso isso segundo o referido autor. Serão estes mesmos os efeitos da reforma? Antes dos números, vejamos no que consiste a reforma. 
Em seu parecer sobre o projeto de lei original que tramitou na Câmara, o deputado Rogério Marinho alegou que a CLT, de 1943, estava obsoleta e não corresponderia aos desafios do tempo presente. Aduziu à necessidade de uma "modernização" da CLT:

O Substitutivo apresentado não está focado na supressão de direitos, mas sim em proporcionar uma legislação mais moderna, que busque soluções inteligentes para novas modalidades de contratação, que aumente a segurança jurídica de todas as partes da relação de emprego, enfim, que adapte a CLT às modernizações verificadas no mundo nesses mais de 70 anos que separam o nascimento da CLT deste momento (MARINHO, 2017, p.20)

A modernização significa neste parecer, entre outras coisas, dar mais liberdade para que as condições de trabalho e remuneração sejam discutidas entre patrão e empregado sem a intermediação do sindicato. $\mathrm{O}$ que for acordado entre as partes prevalecerá sobre o legislado. A tese é que isso não apenas dá mais liberdade para o patrão e o empregado definirem as condições para a formalização do contrato, como também, teria repercussões positivas na redução de conflitos trabalhistas que tanto têm onerado a justiça do trabalho:

\begin{abstract}
De acordo com dados colocados à disposição pelo próprio TST, somente no ano de 2016, as Varas do Trabalho receberam, na fase de conhecimento, 2.756 .159 processos, um aumento de $4,5 \%$ em relação ao ano anterior. Desses, 2.686 .711 foram processados e julgados. A soma da diferença dos processos não julgados no ano com o resíduo já existente nos tribunais totalizou 1.843.336 de processos pendentes de julgamento, em 31 de dezembro de 2016. (...) Somando todos esses números, chegamos ao expressivo número de cerca de 4 milhões de novas ações trabalhistas. (...) A pergunta a ser feita é: o País suporta tal demanda? Até quando os tribunais trabalhistas suportarão esse volume de processos? (MARINHO, 2017, p.21-22)
\end{abstract}

Vê-se que a reforma trabalhista não apenas flexibiliza, como também, cria barreiras para a resolução de litígios na Justiça do Trabalho. Modernizar a legislação significa evitar a busca do poder judiciário para resolver litígios e adotar resoluções extrajudiciais.

Em verdade, há uma desconfiguração das relações de trabalho e de garantias para o trabalhador a começar pela jornada de trabalho. O Decreto-Lei $\mathrm{N}^{0} 5.452$ de $1^{\circ}$ de maio de 1943 que estabelece a CLT - definia, em seu artigo 58, que a jornada de trabalho corresponde a 8 horas diárias. Com a mudança, o trabalhador pode ter uma jornada de 12 horas ininterruptas com descanso de 36 horas. Além disso, o entendimento vigente é que o tempo despendido para locomoção de casa para o trabalho deveria ser computado como jornada de trabalho, mas o relator entendeu que "por não ser tempo à disposição do empregador, não integrará a jornada de trabalho" (MARINHO, 2017, p.36).

Acrescente-se ao tema da jornada a possibilidade de que as horas extras sejam convertidas em folgas através do banco horas. A mudança, de acordo com a nova redação, é que será permitida a pactuação, por acordo individual, desde que a compensação ocorra no máximo em seis meses sem 
a necessidade de o empregador comunicar ao Ministério do Trabalho as horas extras laboradas que ultrapassem o limite legal.

A mudança nas formas de contratação, sem dúvidas, é um dos pontos mais delicados da reforma. O discurso empresarial alega a excessiva burocracia e carga de responsabilidades patronais que inviabiliza a abertura de postos de trabalhos formais.

O teletrabalho - inserido no artigo 75-A - constitui uma modalidade de contrato que, na lógica dos que aprovaram a nova legislação, é consequência do desenvolvimento tecnológico que permite ao trabalhador executar sua função fora das dependências de seu empregador através das tecnologias da informação. Quando esse empregado precisar ir às dependências de seu patrão para executar tarefas pertinentes a sua função, não haverá descaracterização do teletrabalho. Estes trabalhadores estão excluídos das normas da CLT em relação ao limite de jornada de trabalho e o registro das horas trabalhadas e das mediadas de saúde e segurança no trabalho.

Outra forma contratual é o trabalho em jornada parcial. Embora já existisse esta modalidade de contato desde os anos 1990, a nova redação estende o tempo de trabalho de 25 para 30 horas sem previsão de horas extra ou para 26 horas semanais com previsão de até 6 horas extras. Neste último caso, a jornada poderia chegar às 32 horas.

Vejamos, agora, no que consiste o trabalho intermitente. Esta modalidade, que não existe na CLT, é inserida pelo artigo 452-A e consiste no emprego pago por horas trabalhadas, mas, contemplando garantias como previdência, férias e FGTS. O curioso da proposta é que, ao assinar este tipo de contato o trabalhador aguarda a sua convocação para o trabalho e, caso aceite a convocação e não compareça, este trabalhador pagará ao seu empregador uma multa de $50 \%$ da remuneração que seria recebida.

A terceirização, que havia sido regulada recentemente pela Lei 13.429/2017, ganhou reforços no PLC 38/17 do Senado. Se antes a terceirização estava limitada às atividades secundárias, com o artigo 4-A do PLC 38/17, as atividades principais também poderão ser terceirizadas. O inciso I do referido artigo diz que os trabalhadores terão os mesmos direitos à alimentação garantida aos empregados da contratante, quando oferecida em refeitórios; à utilização dos serviços de transporte; ao acesso ao atendimento médico ou ambulatorial existente nas dependências da contratante ou em local por ela designado e à inclusão nos treinamentos da empresa para exercício da sua função quando for necessário. No inciso II, fala-se em acesso igualdade quanto à garantia de inclusão dos terceirizados em medidas de proteção aos riscos de acidentes e danos à saúde.

No artigo 442-B afirma-se que a contratação do autônomo poderá ocorrer com ou sem exclusividade, de forma contínua ou não, o que não significa que o trabalhador assuma a qualidade 
de empregado. Este item foi aprovado com a ressalva de que, por meio de medida provisória, o Presidente da República eliminaria a exigência de exclusividade o que, efetivamente, não ocorreu.

Além destas formas de contato de trabalho, algumas inéditas, a reforma trabalhista também apresenta mudanças quanto às formas de remuneração. Vejamos. O artigo 611-A estabelece a prevalência do acordo coletivo sobre a legislação vigente inclusive quanto ao rebaixamento dos próprios salários da categoria conforme o parágrafo $3^{\circ}$ referido do artigo que diz que "Se for pactuada cláusula que reduza o salário ou a jornada, a convenção coletiva ou o acordo coletivo de trabalho deverão prever a proteção dos empregados contra dispensa imotivada durante o prazo de vigência do instrumento coletivo" (BRASIL, 2017, p.31).

A reforma ainda mexe com pontos delicados que tocam em garantias básicas. A depender do acordo com o seu patrão, o trabalhador pode fracionar as férias em três períodos sendo que um deles não pode ser menor que 14 dias. O intervalo interjornada é reduzido para o máximo de 30 minutos em casos de jornada superior a seis horas. Quanto às mães que amamentam, serão concedidos dois períodos de 30 minutos para amamentação durante os seis primeiros meses da criança.

Um último ponto está relacionado às medidas de segurança e saúde do trabalhador. Uma mudança importante do projeto, contida no parágrafo único do artigo 611-B, diz que a duração do trabalho e os intervalos não são consideradas como normas de saúde, higiene e segurança do trabalho. Outro aspecto muito impactante é a não proibição de mulheres grávidas e lactantes de trabalharem em tarefas e ambientes insalubres.

\section{OS PRIMEIROS NÚMEROS DA IMPLEMENTAÇÃO DA REFORMA TRABALHISTA NA PARAÍBA}

Comecemos pelo quadro geral do emprego na Paraíba fazendo uma comparação ao longo dos trimestres que se sucedem de 2015 até o ano corrente. 
Gráfico 1: Evolução das Taxas de ocupação e desocupação na Paraíba

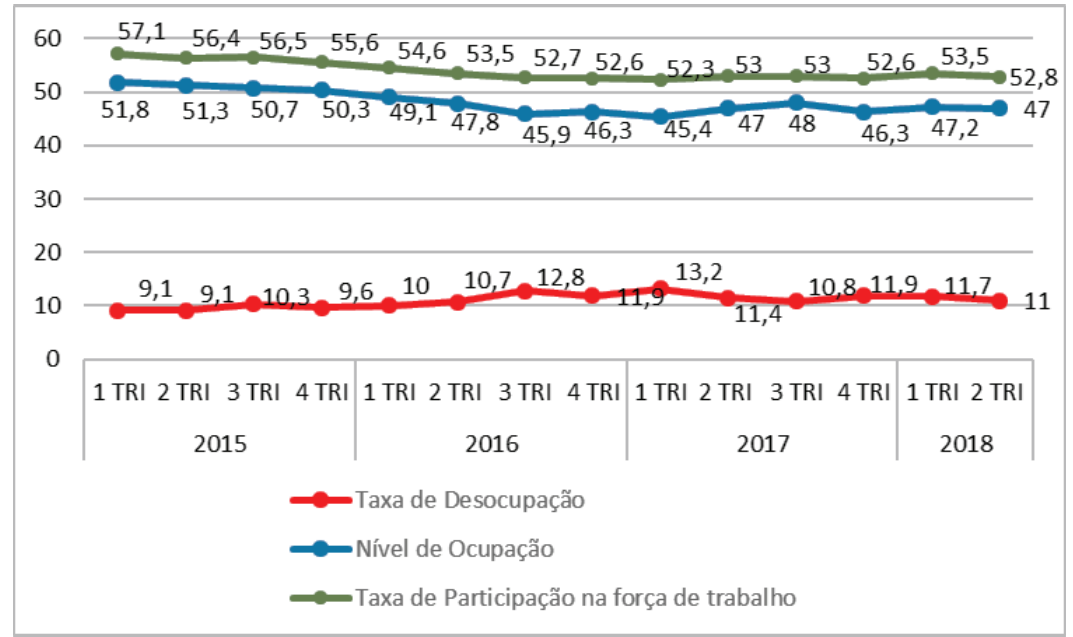

Fonte: IBGE/PNADC (2018)

O ano de 2015 foi de muita instabilidade com a preparação do cenário para a derrubada do governo da Presidenta Dilma. Dos muitos argumentos que embasaram a aprovação do impeachment, estava a crise econômica e a quebra do país pelo PT. Retóricas políticas à parte, do ponto de vista deste indicador do gráfico acima, no Estado da Paraíba, o cenário econômico revelou uma situação em que a média da taxa de desocupação foi menor do que nos períodos subsequentes, inclusive, no período posterior à aprovação da reforma. Veja, neste caso, que a taxa de desocupação, na média dos 4 trimestres de 2015, foi de $9,53 \%$ enquanto que, no ano seguinte, foi de 11,4\%, em 2017 foi de 11,8 e, do $4^{\circ}$ trimestre de 2017 ao segundo do corrente ano - em que vigora a reforma - essa taxa é de 11,5\%, portanto, maiores do que no ano de 2015.

No comparativo entre Brasil, Nordeste e Paraíba, vemos uma proximidade muito grande entre nosso estado e a Região Nordeste no que se refere ao quadro do nível de ocupação da população com 14 anos ou mais. A visualização é clara no gráfico seguinte. 
Gráfico 2: Comparativo do nível de ocupação Brasil, Nordeste e Paraíba (em \%)

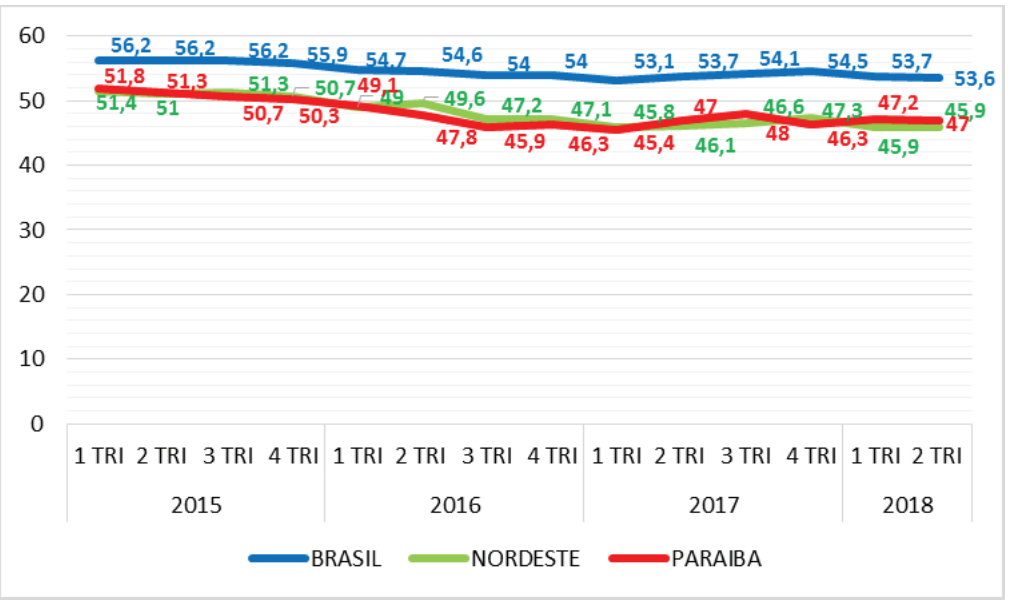

Fonte: IBGE/PNADC (2018)

O nível de ocupação vem num quadro de estabilidade sendo a situação da Paraíba similar à do Nordeste e, ambas, bastante inferiores ao quadro nacional. E isto se verifica, de certa maneira, também no balanço das admissões e desligamentos referentes ao período em que se discutia e se aprovava a reforma. Vejamos:

Gráfico 3: Registro das movimentações segundo o CAGED no período da Reforma

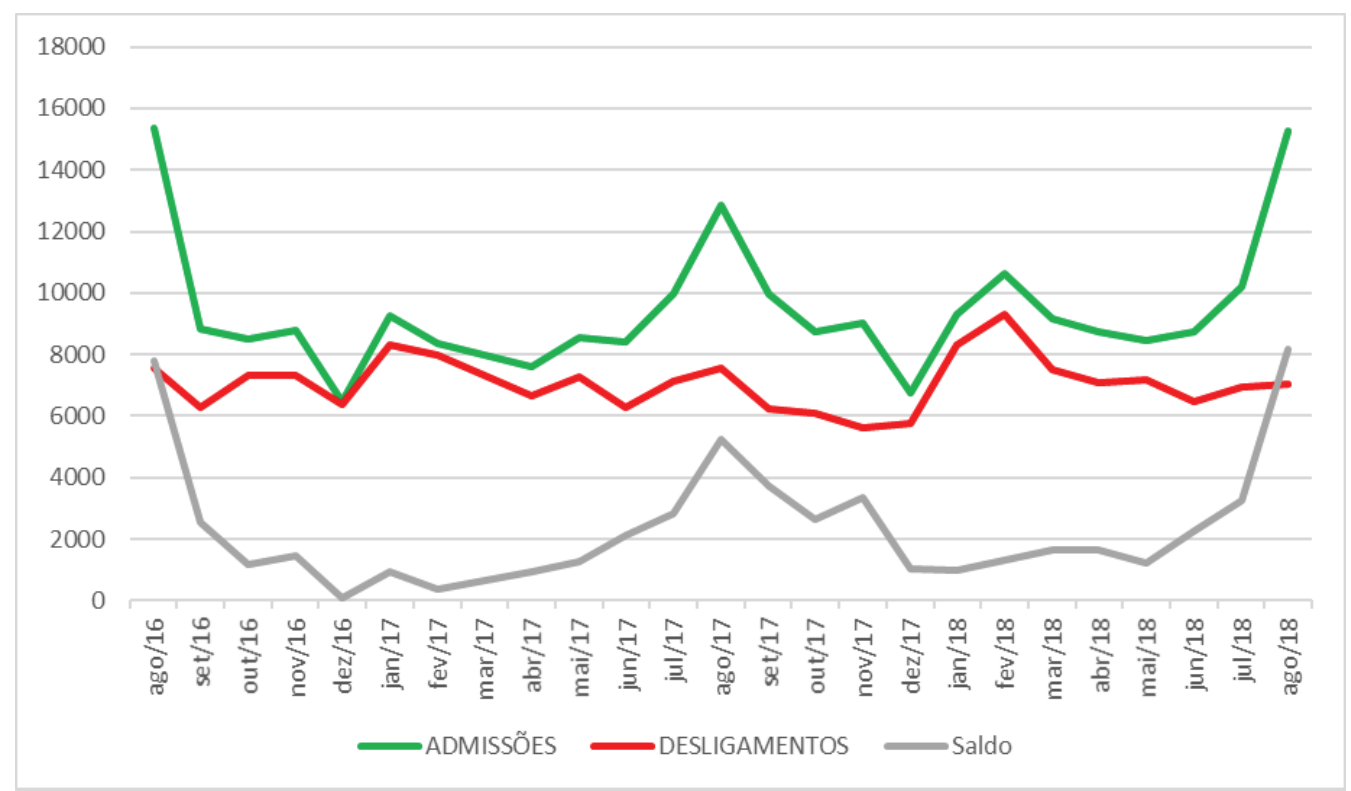

Fonte: MTE/CAGED (2018)

Mas, como destacam Filgueiras et al (2018), a aparência de números alentadores esconde o trabalho sem carteira assinada e o trabalho por conta própria. São evidências da marcha da precarização, portanto, da perda de direitos e piora das condições de trabalho que crescem com as 
novas modalidades de contrato e, por outro lado, também é evidência da manutenção de atividades historicamente precárias, com poucas conquistas de direitos, e que passam a operar ainda mais largamente. É sob este segundo prisma que observamos os efeitos da reforma na Paraíba uma vez que estas funções já eram muito presentes e passaram a contar com a legalidade conferida pela reforma.

Tabela 1: Perfil do emprego segundo a condição da ocupação (em \%).

\begin{tabular}{|c|c|c|c|c|c|c|c|c|c|c|c|c|c|c|}
\hline \multirow[b]{2}{*}{ REGISTRO } & \multicolumn{4}{|c|}{2015} & \multicolumn{4}{|c|}{2016} & \multicolumn{4}{|c|}{2017} & \multicolumn{2}{|c|}{2018} \\
\hline & $\begin{array}{l}1^{\circ} \\
\text { TRI }\end{array}$ & $\begin{array}{l}2^{\circ} \\
\text { TRI }\end{array}$ & $\begin{array}{c}3^{\circ} \\
\text { TRI }\end{array}$ & $\begin{array}{l}4^{\circ} \\
\text { TRI }\end{array}$ & $\begin{array}{l}1^{\circ} \\
\text { TRI }\end{array}$ & $\begin{array}{l}2^{\circ} \\
\text { TRI }\end{array}$ & $\begin{array}{c}3^{\circ} \\
\text { TRI }\end{array}$ & $\begin{array}{l}4^{\circ} \\
\text { TRI }\end{array}$ & $\begin{array}{l}1^{\circ} \\
\text { TRI }\end{array}$ & $\begin{array}{l}2^{\circ} \\
\text { TRI }\end{array}$ & $\begin{array}{c}3^{\circ} \\
\text { TRI }\end{array}$ & $\begin{array}{l}4^{\circ} \\
\text { TRI }\end{array}$ & $\begin{array}{l}1^{\circ} \\
\text { TRI }\end{array}$ & $\begin{array}{c}2^{\circ} \\
\text { TRI }\end{array}$ \\
\hline $\begin{array}{c}\text { Privado } \\
\text { Com } \\
\text { carteira }\end{array}$ & 24,28 & 24,40 & 24,89 & 24,25 & 23,96 & 24,30 & 23,66 & 24,51 & 23,19 & 22,66 & 22,14 & 22,02 & 22,10 & 22,09 \\
\hline $\begin{array}{c}\text { Privado Sem } \\
\text { Carteira } \\
\end{array}$ & 17,52 & 17,36 & 16,53 & 18,33 & 17,88 & 17,68 & 18,59 & 17,38 & 17,60 & 16,81 & 16,79 & 17,39 & 17,35 & 17,92 \\
\hline Doméstico & 6,38 & 6,04 & 6,78 & 6,87 & 6,67 & 7,15 & 7,41 & 7,33 & 7,18 & 7,31 & 7,10 & 7,21 & 7,26 & 6,61 \\
\hline $\begin{array}{c}\text { Setor } \\
\text { Público } \\
\end{array}$ & 17,46 & 16,98 & 17,23 & 17,44 & 16,97 & 17,81 & 18,04 & 17,72 & 18,50 & 18,67 & 18,59 & 18,54 & 17,74 & 17,99 \\
\hline Empregador & 3,19 & 2,89 & 2,98 & 2,48 & 2,72 & 3,31 & 4,05 & 3,94 & 3,52 & 4,25 & 4,26 & 4,57 & 4,55 & 4,83 \\
\hline $\begin{array}{c}\text { Conta } \\
\text { Própria } \\
\end{array}$ & 26,72 & 27,67 & 27,04 & 26,73 & 27,33 & 26,03 & 24,97 & 25,87 & 26,71 & 26,45 & 27,31 & 26,79 & 27,11 & 26,39 \\
\hline $\begin{array}{c}\text { Trabalhador } \\
\text { auxiliar }\end{array}$ & 4,44 & 4,65 & 4,56 & 3,88 & 4,47 & 3,71 & 3,29 & 3,26 & 3,31 & 3,85 & 3,81 & 3,48 & 3,89 & 4,17 \\
\hline
\end{tabular}

Fonte: MTE/CAGED(2018)

$\mathrm{Na}$ descrição do quadro nacional Filgueiras et al (2018) comenta o crescimento dos trabalhadores por conta própria em $4,9 \%$ acima taxa de incremento total da ocupação enquanto que os sem carteira assinada cresceram, também em 2018, cerca de $10 \%$. O mercado de trabalho paraibano manteve, com a reforma, sua estrutura de ocupações precárias com considerável número de trabalhadores sem carteira assinada sendo grande parte deste grupo sob a forma de trabalhadores por conta própria.

\section{O TRABALHADOR INTERMITENTE}

A figura do trabalhador intermitente já ganha importância na composição do mercado paraibano assim como o reforço do trabalho parcial. Os intermitentes, segundo os dados que colhemos no CAGED, começam a aparecer no final do primeiro trimestre do ano passado e seu crescimento ocorre largamente como poderemos ver nos dados que seguem. Como vamos comparar a tendência da Paraíba com as do Nordeste e do Brasil, é importante registrar que a nível regional e nacional, desde novembro de 2017, quando não se tem dados sobre a Paraíba, o saldo entre admissões e desligamento, regional e nacional seguiram uma tendência de crescimento que seguiu até abril de 2018. No nosso Estado, nos meses de abril e maio temos os primeiros registros e, 
tomando o mês de maio em relação ao de abril, constatamos um avanço do trabalho intermitente, mas, essa tendência sofre alterações que poderemos comparar nos quatro gráficos que seguem.

GRÁFICO 4

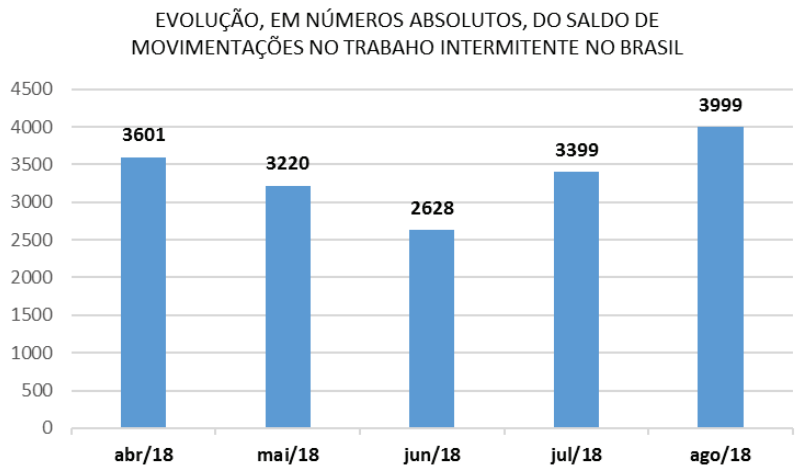

Fonte: MTE/CAGED (2018)

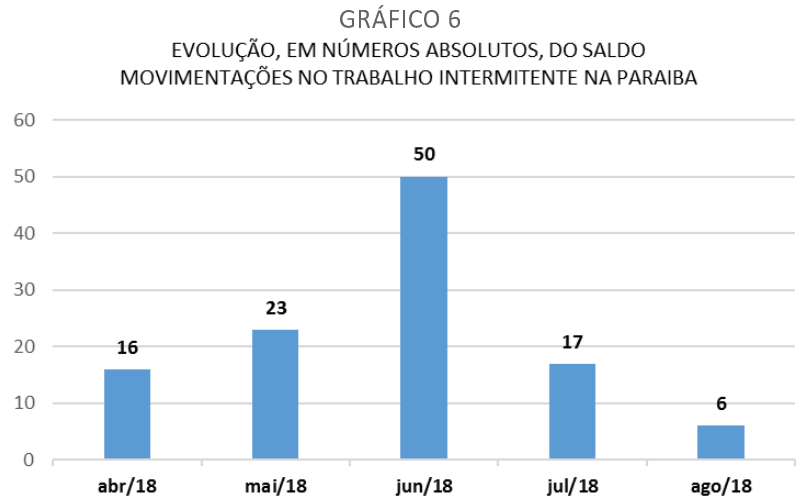

Fonte: MTE/CAGED (2018)
GRÁFICO 5

EVOLUÇ̃̃O, EM NÚMEROS ABSOLUTOS, DO SALDO DE MOVIMENTAÇÕES NO TRABALHO INTERMITENTE NO NORDESTE

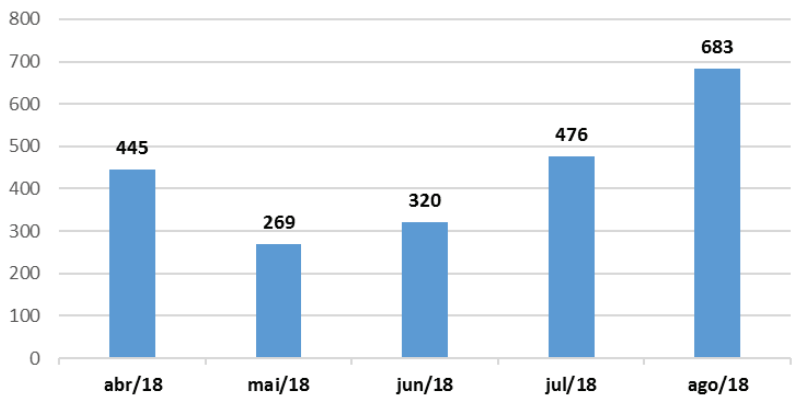

Fonte: MTE/CAGED (2018)

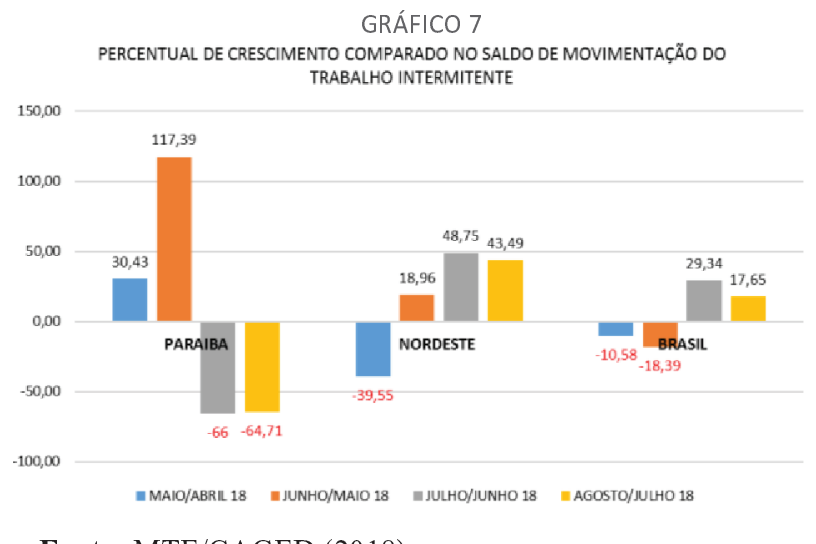

Fonte: MTE/CAGED (2018)

Se, no primeiro trimestre, houve um crescimento que chegou a $117 \%$, por outro, entre o segundo e terceiro trimestres, observou-se um crescimento negativo no saldo de movimentações do trabalho intermitente contrariando a tendência regional e nacional. No caso paraibano, a nossa hipótese para explicação deste comportamento do trabalho intermitente diz respeito a uma redistribuição dos que saem da condição de intermitente para outro tipo de trabalho sem carteira assinada, ou seja, tem havido apenas recomposições do trabalho precário em nosso Estado. Vejamos alguns dados do perfil destes trabalhadores. 
Gráfico 8: perfil dos intermitentes quanto ao gênero (em termos percentuais)

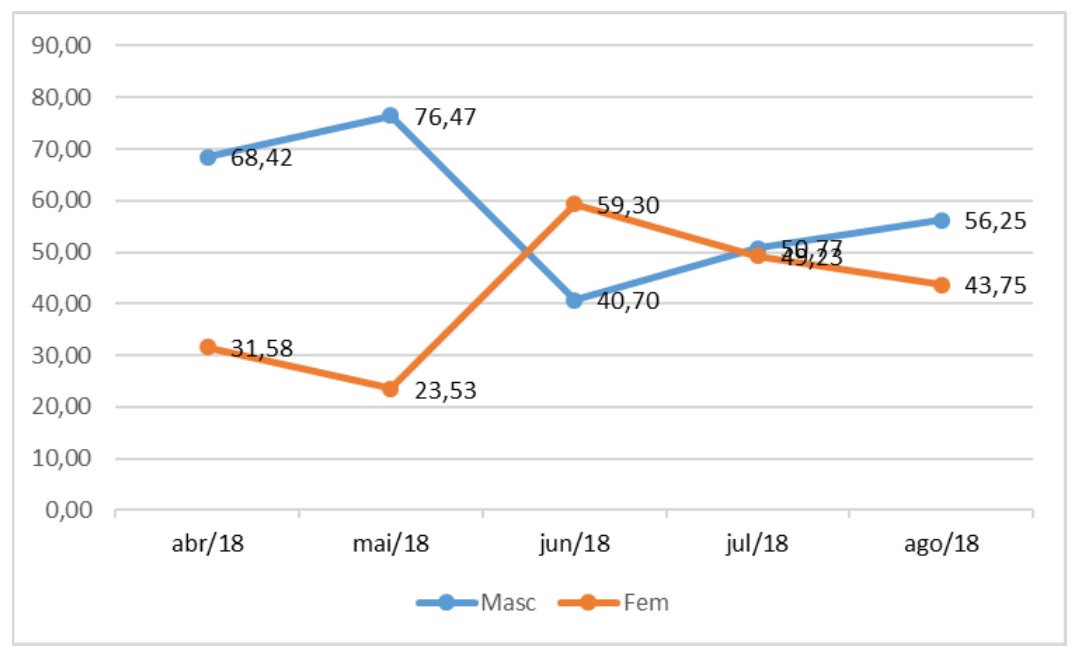

Fonte: MTE/CAGED(2018)

Está claro a predominância dos homens em relação às mulheres quanto ao trabalho intermitente, com exceção do período junho - julho em que se viu o número de mulheres liderar com uma queda no mês seguinte. Vejamos o perfil de escolaridade.

Gráfico 9: Perfil dos trabalhadores intermitentes quanto a escolaridade

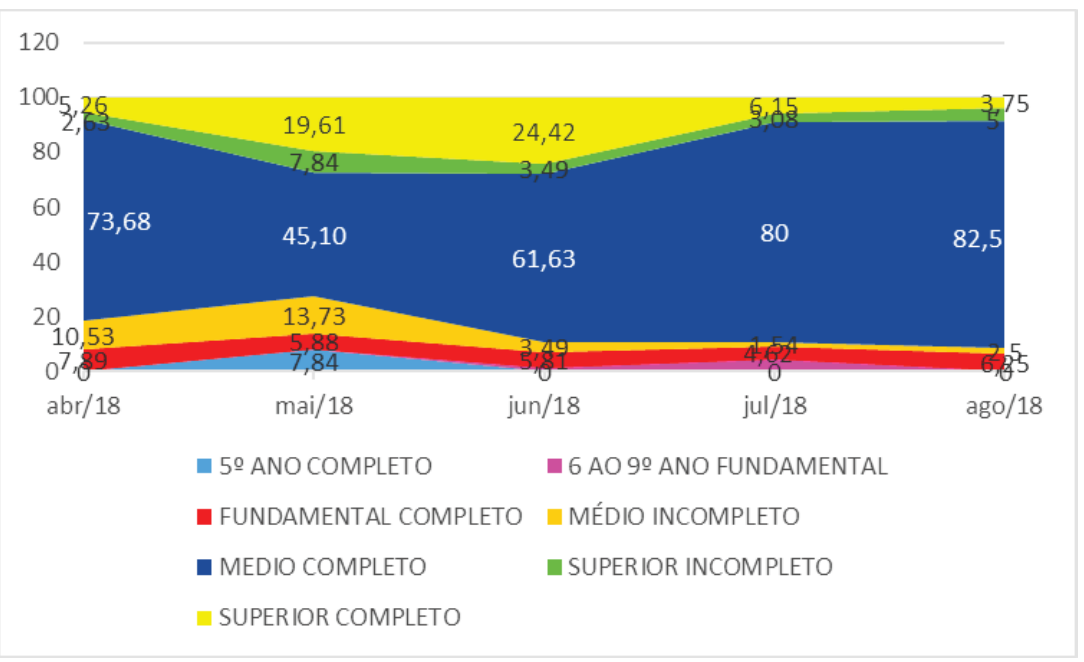

Fonte: MTE/CAGED (2018)

Majoritariamente, os trabalhadores intermitentes têm ensino médio com uma variação negativa entre maio e junho que não foi suficiente para eliminar essa maioria. São, basicamente, trabalhadores de ensino médio e jovens sendo este último indicador verificado abaixo: 
Gráfico 10: média de faixa etária verificada no período de abril a agosto de 2018

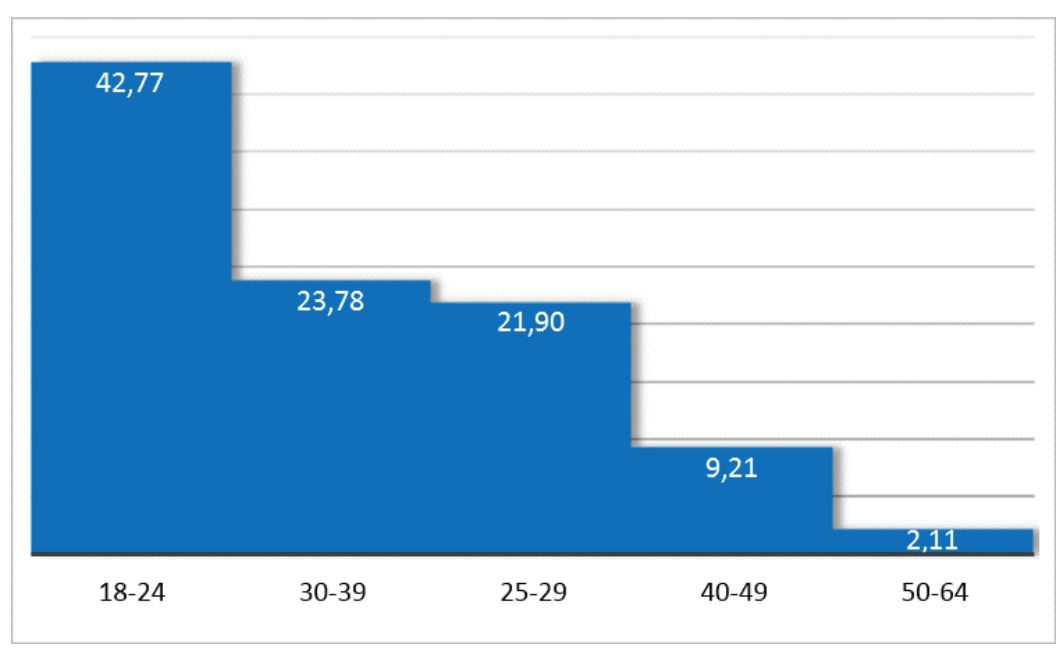

Fonte: MTE/CAGED (2018)

Em relação à faixa salarial, estes trabalhadores não recebem mais que um salário e meio conforme gráfico seguinte.

Gráfico 11: Faixa salarial dos intermitentes

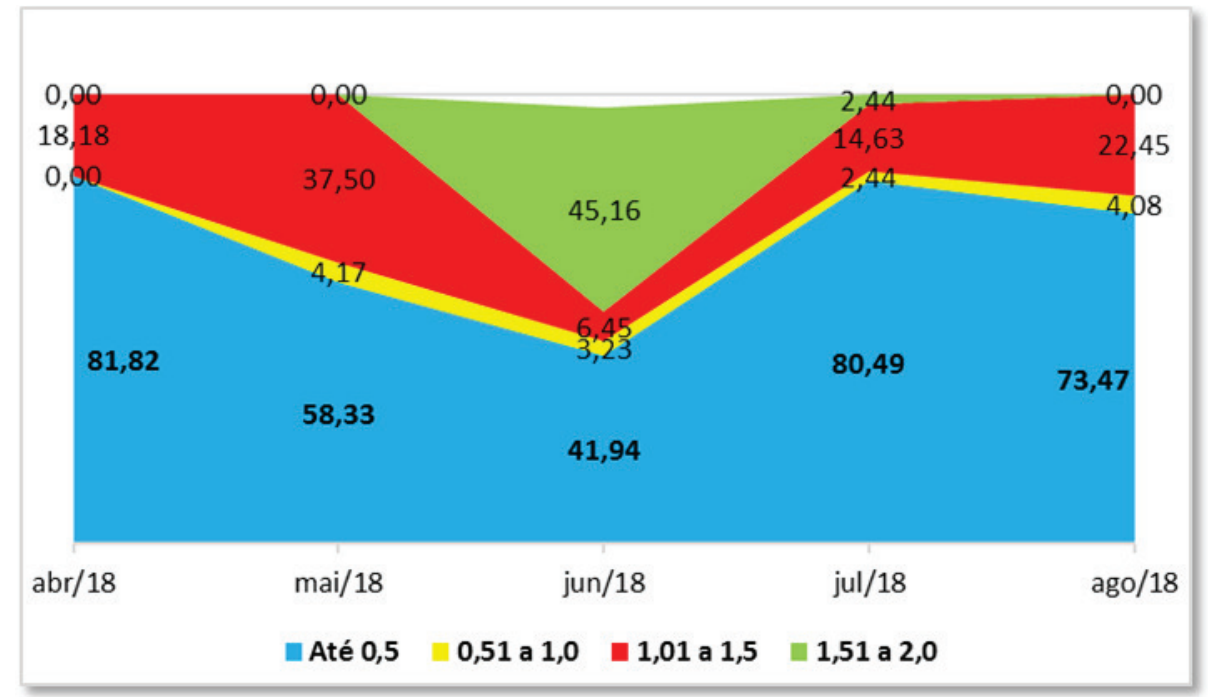

Fonte: MTE/CAGED (2018)

Com exceção de junho de 2018, nos demais meses do período em destaque no gráfico acima, a faixa de meio salário mínimo é a preponderante entre este segmento no Estado da Paraíba. A média histórica do período é de $67 \%$ de trabalhadores recebendo até meio salário enquanto que 19,84\% recebem entre um salário e meio a 2 salários mínimos. 
Gráfico 13: Taxa de subocupação por insuficiência de horas trabalhadas das pessoas de 14 anos ou mais de idade, na semana de referência

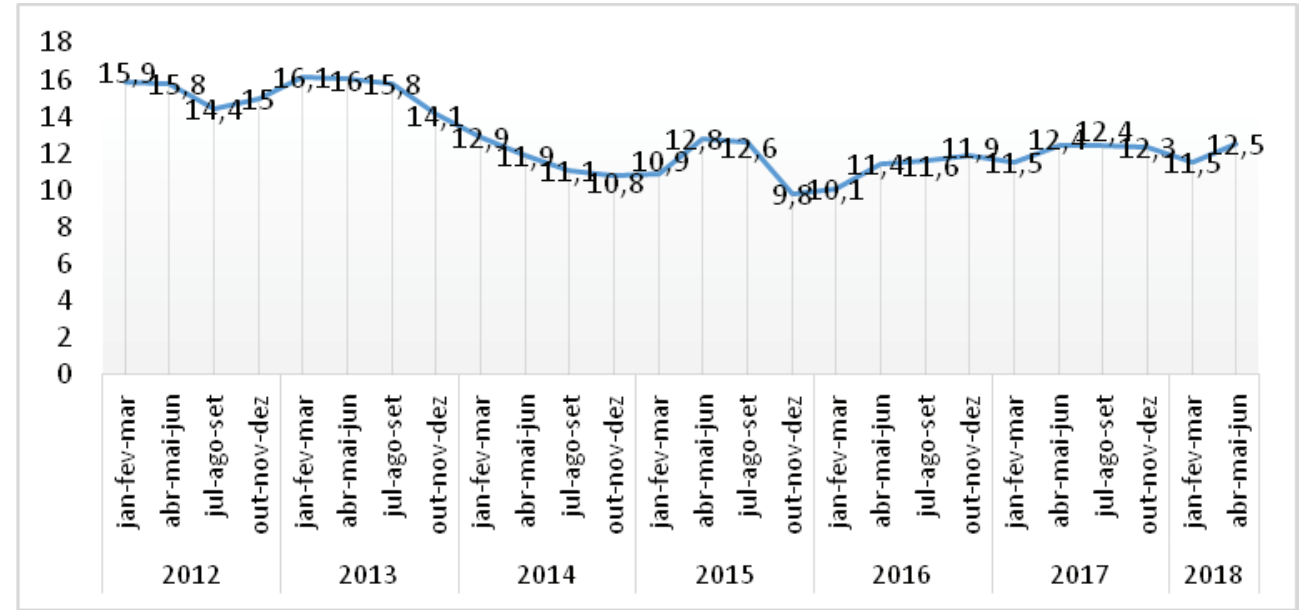

Fonte: IBGE/PNADC (2018)

A jornada dos trabalhadores intermitentes na Paraíba está, majoritariamente, em 12 horas trabalhadas. Este indicador, na opinião de especialistas (Filgueiras et al, 2018), evidencia a precarização das formas de inserção no mercado de trabalho algumas das quais, sequer, podem "ser consideras propriamente como empregos, dada a subocupação por insuficiência de horas de trabalho" (Filgueiras et al 2018, p. 143).

Para encerrar esta caracterização, indicamos quais as ocupações que mais empregaram na modalidade trabalho intermitente.

Tabela 2: Ocupações que mais empregaram na modalidade trabalho intermitente.

\begin{tabular}{|l|l|}
\hline \multicolumn{1}{|c|}{ OCUPAÇÃO } & TOTAL \\
\hline Repórter de Rádio e Televisão & 1 \\
\hline Professor Pratico no Ensino Profissionalizante & 3 \\
\hline Assistente de Vendas & $\mathbf{3 6}$ \\
\hline Operador de Caixa & 2 \\
\hline Garçom & 2 \\
\hline Atendente de Lanchonete & $\mathbf{6}$ \\
\hline Auxiliar nos Serviços de Alimentação & 1 \\
\hline Promotor de Vendas & 7 \\
\hline Atendente de Farmácia - Balconista & 2 \\
\hline Frentista & 1 \\
\hline Atendente de Lojas e Mercados & 4 \\
\hline Pedreiro & 6 \\
\hline Armador de Estrutura de Concreto Armado & 1 \\
\hline Eletricista de Instalações & 1 \\
\hline Montador de Estruturas Metálicas & 1 \\
\hline Instalador-Reparador de Equipamentos de Comutação em Telefonia & 1 \\
\hline
\end{tabular}




\begin{tabular}{|l|l|}
\hline Motorista de Caminhão (Rotas Regionais e Internacionais) & 1 \\
\hline Embalador à mão & 3 \\
\hline Mecânico de Manutenção de Máquinas, em Geral & 1 \\
\hline Total & 80 \\
\hline
\end{tabular}

Fonte: MTE/CAGED (2018)

Na Paraíba o comércio e o setor de serviços lideram nas contratações de trabalhadores intermitentes. Especialmente as atividades referentes à vendas, a condição de insegurança do trabalhador é muito acentuada em vista a sazonalidade e as formas de pagamento realizadas com base em metas. É prática corrente na Paraíba que muitas pessoas sejam chamadas às lojas para trabalharem na condição de "experiência", ou seja, não há vínculo de trabalho formal e sua permanência no empreendimento depende da rotatividade de trabalhadores na empresa ou do bom desempenho da pessoa nas vendas. Essa modalidade de contrato intermitente deu a esta dinâmica praticamente legalidade permitindo o empregador desligar com mais facilidade seus trabalhadores.

\section{OS TRABALHADORES PARCIAIS NA PARAÍBA}

O trabalho parcial já é uma modalidade conhecida, porém, no presente artigo olharemos este indicador a partir do contexto de reforma, especialmente, a partir do momento em que se pode comparar com o número de registros de trabalho intermitente. Isso para termos uma comparação e identificarmos variações ou permanência.

Gráfico 14: Movimentações do trabalho parcial na Paraíba (em números absolutos)

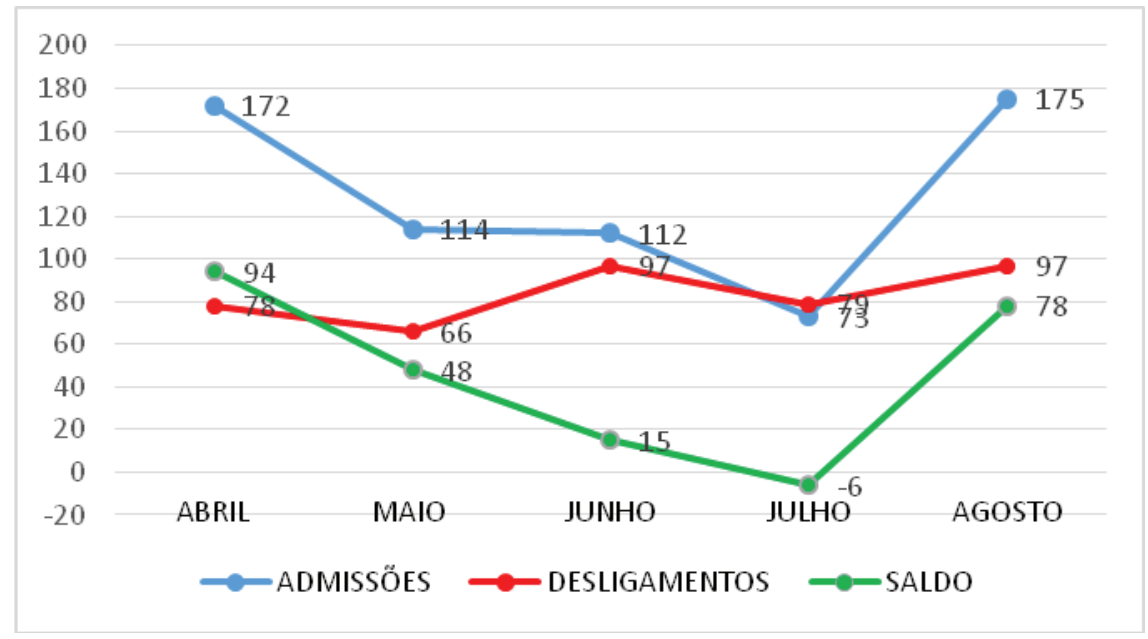

Fonte: MTE/Caged (2018)

O número de admissões foi superior ao de desligamentos ao longo do período observado, com exceção, do mês de julho. Deste contingente, a maioria é de mulheres: 
Gráfico 15: Característica dos trabalhadores periciais quanto ao gênero em 2018 (\%)

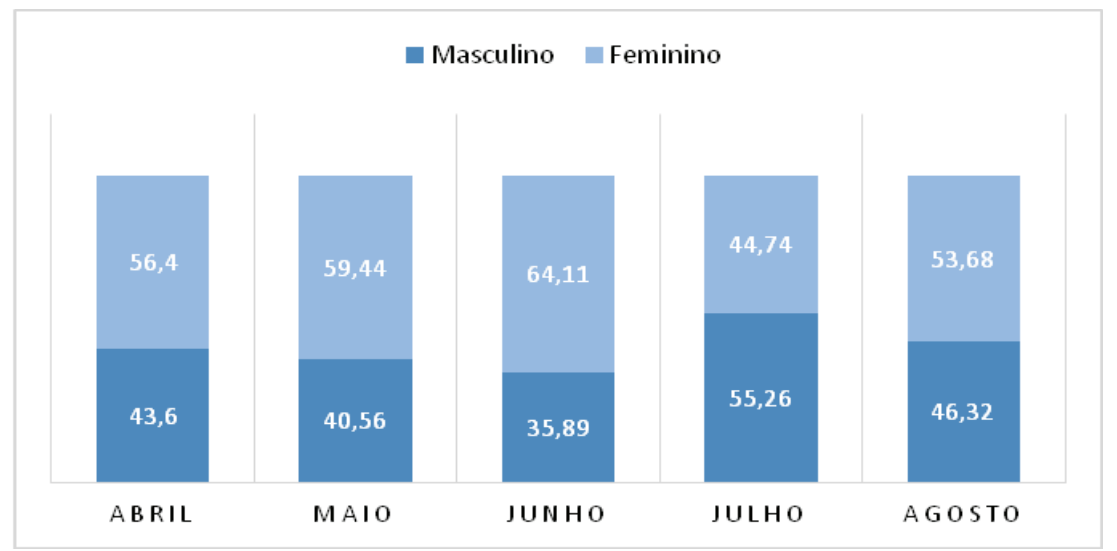

Fonte: MTE/Caged (2018)

Neste tipo de contrato estão, em maior percentual, os trabalhadores experientes conforme podemos depreender do gráfico abaixo:

Gráfico 16: caracterização dos trabalhadores parciais quanto à faixa etária (em \%)

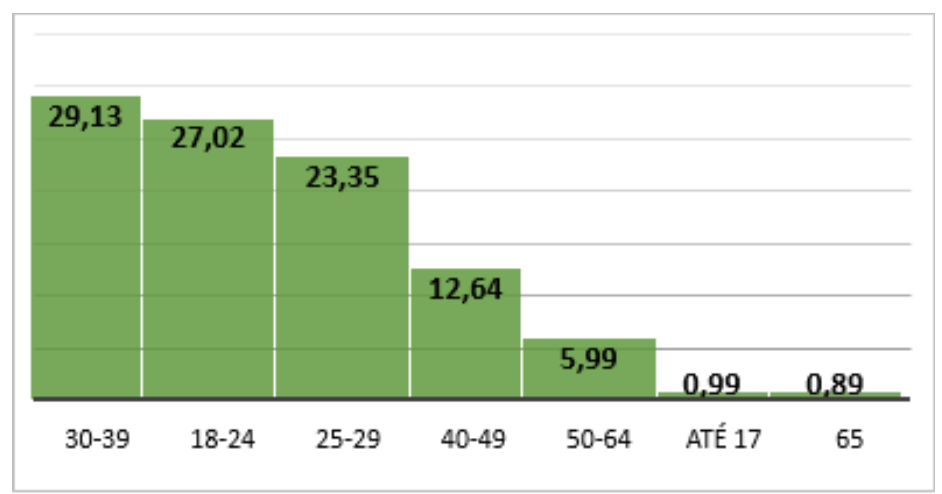

Fonte: MTE/Caged (2018)

Outra característica é a escolaridade dos trabalhadores parciais que revela um quadro de escolarização mais elevado em comparação com os intermitentes:

Gráfico 17: nível de escolaridade dos trabalhadores parciais na Paraíba (\%)

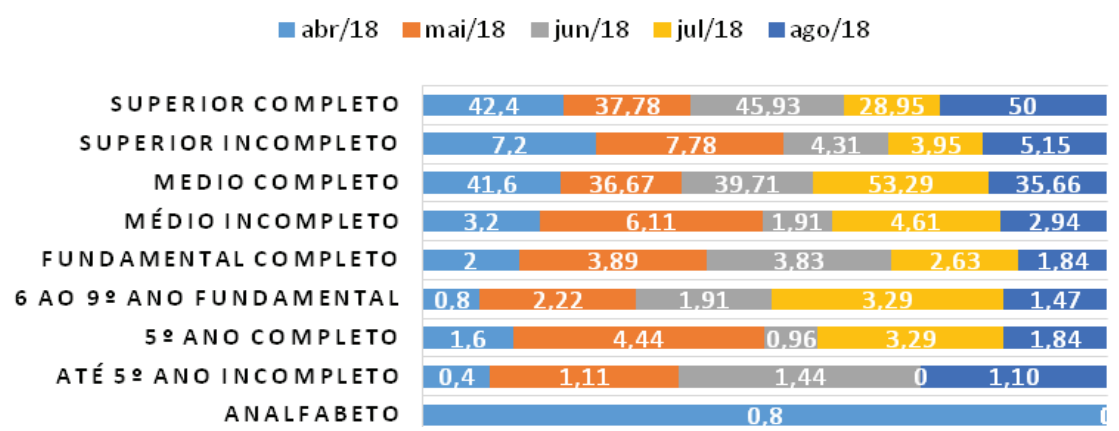

Fonte: MTE/Caged (2018) 
O gráfico é muito claro quanto ao nível de escolaridade majoritário dos parciais estar em torno do ensino médio e o ensino superior completo. Vejamos quais as ocupações que mais absorvem estes trabalhadores:

Tabela 3: principais ocupações de trabalhadores parciais na Paraíba

\begin{tabular}{|l|r|}
\hline OCUPAÇÃO & TOTAL \\
\hline Farmacêutico & 5 \\
\hline Preparador Físico & 7 \\
\hline $\begin{array}{l}\text { Professor da Educação de Jovens e Adultos do Ensino Fundamental (Primeira } \\
\text { à Quarta Série) }\end{array}$ & 35 \\
\hline Professor de Nível Superior do Ensino Fundamental (Primeira à Quarta Série) & 6 \\
\hline Professor de Educação Física do Ensino Fundamental & 5 \\
\hline Professor de Biologia no Ensino Médio & 4 \\
\hline Professor de Língua Inglesa & 5 \\
\hline Professor de Literatura Inglesa & 4 \\
\hline Professor de Serviço Social do Ensino Superior & 7 \\
\hline Colorista Têxtil & 6 \\
\hline Professor de Nível Médio no Ensino Fundamental & 4 \\
\hline Professor de Nível Médio no Ensino Profissionalizante & 4 \\
\hline Professores de Cursos Livres & 6 \\
\hline Auxiliar de Escritório, em Geral & 4 \\
\hline Assistente Administrativo & 7 \\
\hline Recepcionista, em Geral & 8 \\
\hline Trabalhador de Serviços de Limpeza e Conservação de Áreas Publicas & 5 \\
\hline Faxineiro & 12 \\
\hline Porteiro de Edifícios & 6 \\
\hline Vigia & 4 \\
\hline Vendedor de Comercio Varejista & 5 \\
\hline Repositor de Mercadorias & 19 \\
\hline
\end{tabular}

Fonte: MTE/CAGED

Existe, na lista acima, um conjunto de ocupações que não são exigentes quanto ao nível de escolaridade a exemplo de faxineiro, recepcionista em geral, repositor de mercadorias entre outras. A diferença em relação aos intermitentes, é que existe um número de ocupações parciais de escolaridade mais elevada como farmacêutico, professor e engenheiro. Resta saber o que isso significa em termos de carga horária e remuneração. 
Gráfico 18: faixa de horas trabalhadas na Paraíba

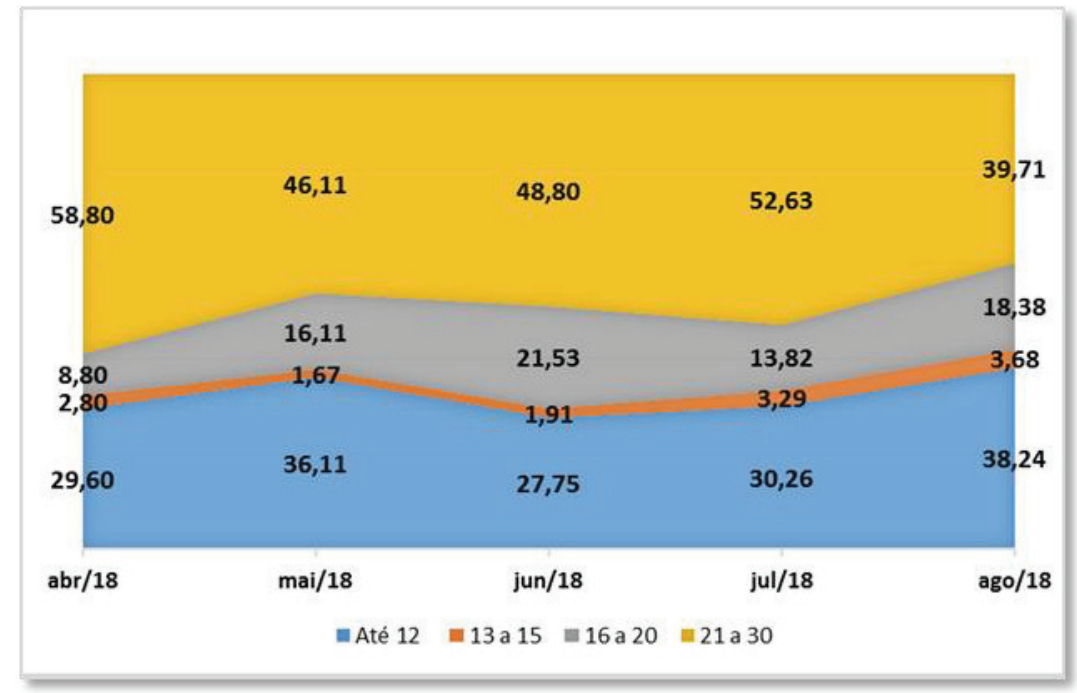

Fonte: MTE/GACED

Os parciais trabalham, na maioria dos casos, chegando a 30 horas semanais havendo, por outro lado, um percentual significativo de trabalhadores que desempenham suas ocupações em jornadas de até 12 horas. Em relação à faixa de remuneração temos um quadro que continua a revelar a precarização do trabalho.

Gráfico 19: Faixa de remuneração dos trabalhadores parciais na Paraíba (em \%)

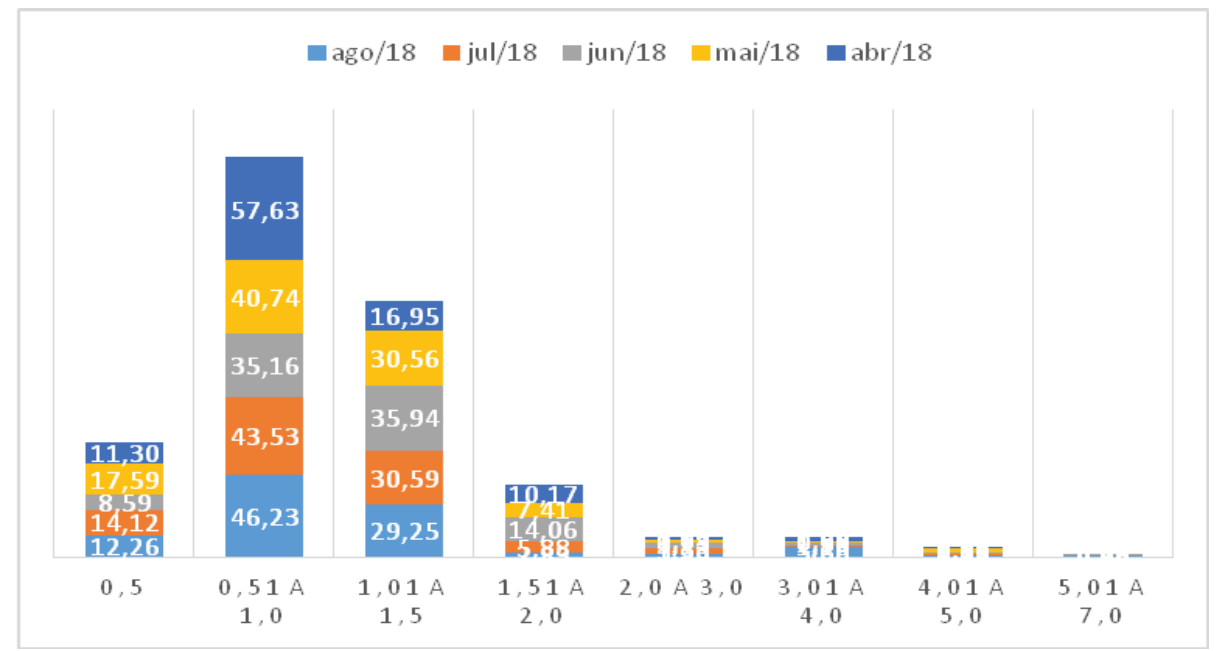

Fonte: MTE/CAGED

A despeito de estarem neste grupo os trabalhadores com diploma de nível superior (em média, a escolaridade dos parciais é de $40 \%$ de pessoas com nível superior), portanto, exercendo funções mais especializadas que poderiam resultar em remunerações mais elevadas, a instabilidade e a fragmentação da jornada concorrem para o rebaixamento do valor do salário. Resulta disso que 
o universo de trabalhadores parciais recebeu, no período de abril a agosto de 2018 em torno de 0,51 a 1,5 salário. Aponta este fato para a necessidade de se revezarem entre empregos distintos com a finalidade de receberem o maior nível de renda. Isso envolve, de certa maneira, maior desgaste do trabalhador que precisa apresentar mais resultados, ter mais patrões, bater metas. É, portanto, mais uma evidência do reforço da precarização do trabalho.

\section{O TRABALHO POR CONTA PRÓPRIA}

O crescimento do trabalho por conta própria tem sido visto como um dos mecanismos de precarização e flexibilização cujos efeitos são a eliminação de vínculos empregatícios transformando o trabalhador em empreendedor de si ao mesmo tempo em que permanece submisso às empresas uma vez que a prestação do seu serviço depende da demanda do mercado (Krein et al, 2018, p. 106-107). Na Paraíba, o contingente de trabalhadores por conta própria sempre foi significativo e, se recordarmos os dados da tabela 1 acima, veremos que na média histórica dos 4 trimestres de 2015 em diante, esse contingente representou cerca de $26 \%$ da força de trabalho paraibana. Esse contingente vem se mantendo com estabilidade na Paraíba como podemos ver no gráfico abaixo:

Gráfico 20: Pessoas ocupadas na semana de referência como conta própria (números absolutos)

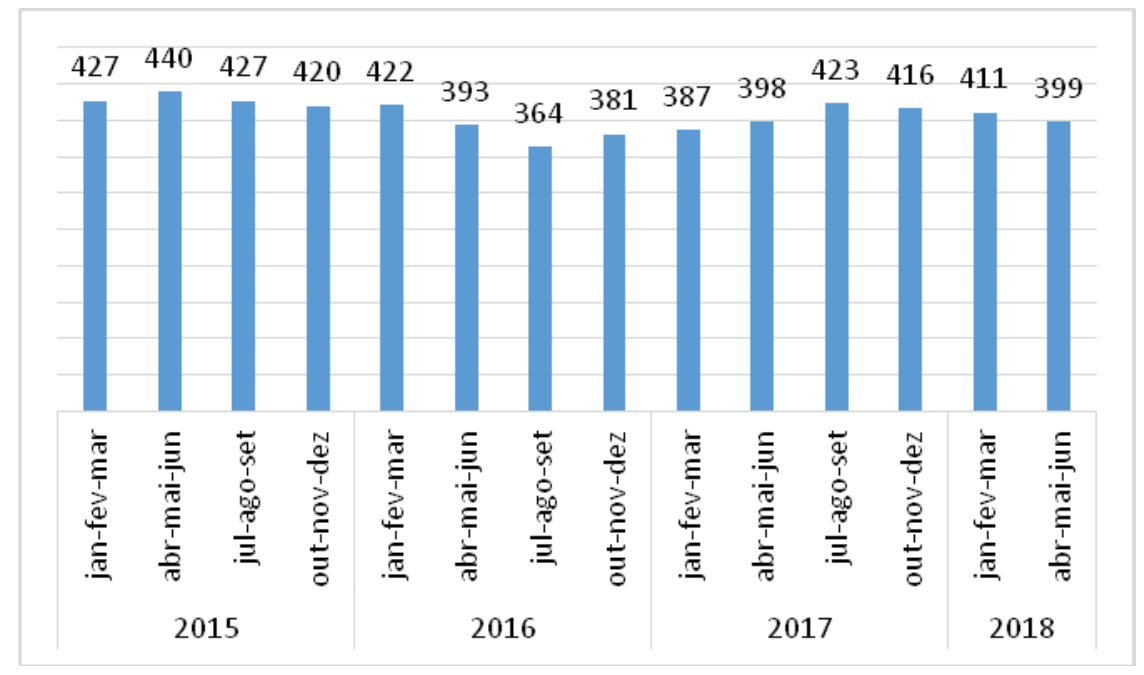

Fonte: MTE/Caged (2018)

Antes da reforma já tínhamos um contingente de contas próprias que continuou sendo importante, embora algumas oscilações pequenas ocorridas a partir do $3^{\circ}$ trimestre de 2017 . Outro dado que precisa ser evidenciado com relação a este grupo diz respeito ao total de trabalhadores com carteira assinada e sem carteira assinada. 
Gráfico 21: Percentual dos trabalhadores por conta própria que não possuem carteira assinada

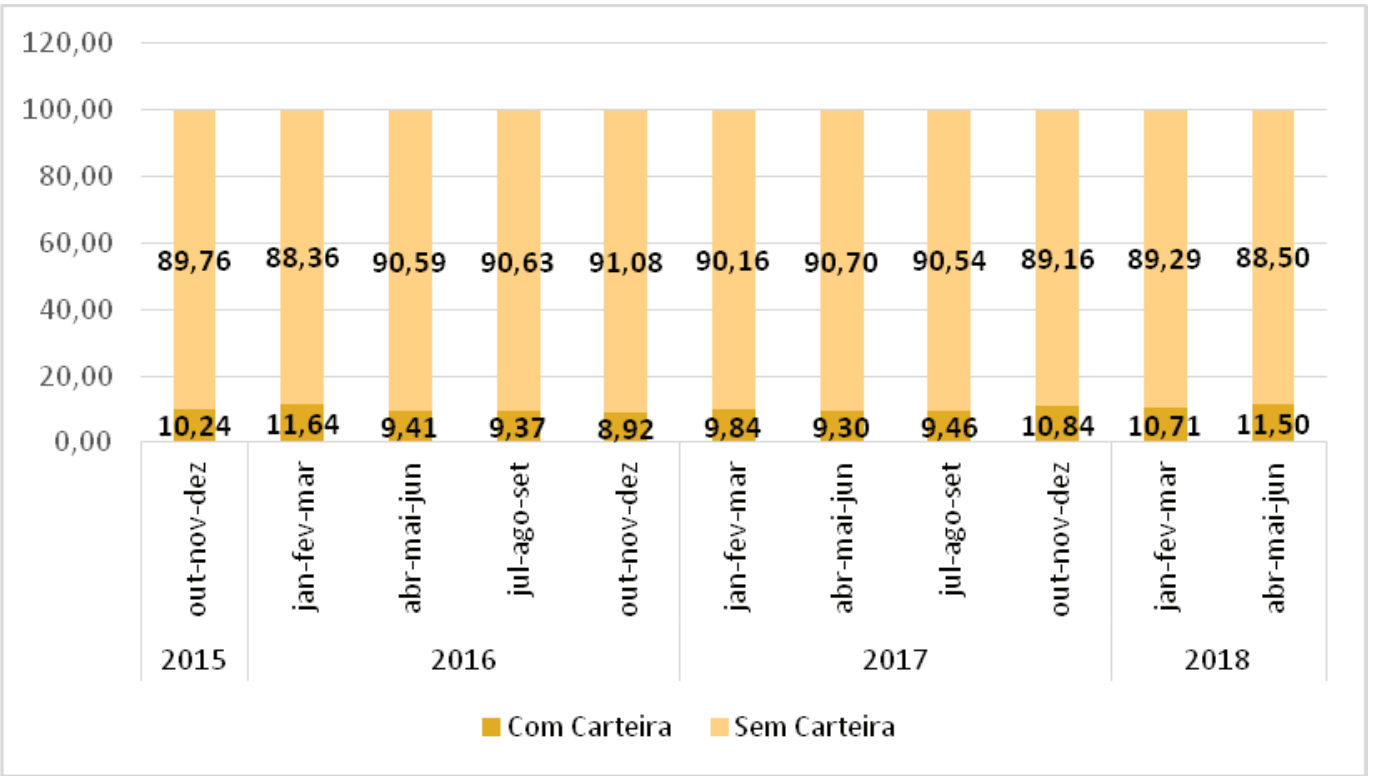

Fonte: MTE/Caged (2018)

Este último indicador que estamos tomando por referência reforça a ideia de que existe uma correlação entre a reforma e a marcha da precarização e da informalização posta em curso nos anos 1990, desacelerada nos anos 2000 e retomada agressivamente no contexto do governo que se instalou pós impeachment de Dilma Roussef. Se nos anos 2000 não tínhamos transformações na CLT a ponto de desconfigurar os vínculos empregatícios, no atual momento, vemos não só uma desconfiguração da relação empregatícia como uma ocultação de possibilidades de enxergar o vínculo mesmo que tenha sido alterada a legislação - e o trabalho por conta própria está sendo uma destas causas disso.

\section{CONSIDERAÇÕES FINAIS}

A despeito de todos os esforços da base aliada do Governo Temer de atrelar esta reforma ao retorno do crescimento econômico e da geração de empregos, não se pode embarcar nesta promessa sem senso crítico, sobretudo, porque sobram evidências do crescimento do trabalho por conta própria sem carteira assinada e de outros mecanismos de emprego disfarçado.

Está em curso um reforço da precarização do trabalho cujos traços flagrantes são os seguintes: a adoção de formas de contratos com menos garantias de direitos, comparando com a legislação vigente, e incluindo novas formas de contratação inadmissíveis segundo os direitos já conquistados pela classe trabalhadora; flexibilização da jornada de trabalho sob regras que deixam o trabalhador mais submisso às determinações de horários e escalas, portanto, com baixa 
possibilidade contestação da jornada o que pode ampliar os riscos à saúde do trabalhador; as condições de trabalho se tornam mais degradantes não só em razão das mudanças na jornada de trabalho, como também, do tratamento dado às normas de saúde e segurança no trabalho as quais, no geral, reduzem as responsabilidades da empresa e elevam a exposição do trabalhador aos riscos; o estímulo à terceirização e os mecanismos de pagamento tendem a reduzir o valor da remuneração recebida pelos trabalhadores e, por último, as possiblidades de organização coletiva, contestação e luta da classe trabalhadora são reduzidas.

No que concerne às formas de contrato - de tempo parcial, temporário, teletrabalho, terceirizado, autônomo - atendendo à lógica do mercado capitalista instaura mecanismos que visam rebaixar os custos da produção e, ao mesmo tempo, intensificar a exploração do trabalho como já vem discutindo há algum tempo por pesquisadores como Antunes (2009). Esta intensificação da exploração dos trabalhadores que vai ser fomentada por contratos que podem ser pagos por produtividade ou cuja longevidade depende "do bom desempenho do trabalhador intermitente".

Aparentemente, o contrato de trabalho intermitente constitui a regulamentação dos biscateiros, pessoas que fazem bicos, mas, na lógica concorrencial do mercado, o trabalhador que realiza um trabalho esporádico pode ser convertido em "permanentemente esporádico", ou seja, sempre à disposição da empresa nas ocasiões em que ela precisar fazer um ajustamento da quantidade de trabalhadores em ação para dar contada da demanda do mercado. Quanto a este tipo de contrato, duvidamos se os seus encargos trabalhistas/previdenciários serão efetivamente recolhidos. Como calcular $1 / 3$ de férias, férias, $13^{\circ}$ salário de um trabalhador que executa um serviço de uma, duas horas diárias em dada empresa? A nosso ver, este tipo de contrato abre porta para burlar a legislação trabalhista na medida em que pode se reduzir o quadro efetivo ou mais estável da empresa absorvendo, por outro lado, grande contingente de trabalhadores intermitentes algo mais ou menos parecido com o caso dos lares que, com a aprovação da legislação sobre emprego doméstico, não quiseram cumprir a lei e trocaram uma empregada doméstica por duas diaristas se eximindo do vínculo trabalhista e das responsabilidades que ele implicaria.

O contrato de tempo parcial amplia para até 32 horas a jornada possível, mas também, pode reduzir o valor pago proporcional ao tempo trabalhado. O teletrabalho não tem limite de jornada de trabalho, pode ser realizado na casa do trabalhador não havendo uma clara separação entre tempo de trabalho e tempo de lazer o que pode resultar no adoecimento, conflitos com filhos carentes de atenção, esposas etc.

Conformou-se uma situação tal que a população passa pelo mercado de trabalho oscilando ente atividades precárias, instáveis, combinadas com bicos, ajudas em atividades familiares, 
empregos com menos direitos, portanto, precarizados e, desta maneira conseguindo um mínimo para reprodução social.

\section{REFERÊNCIAS}

ALVES, Giovanni. Dimensões da precarização do trabalho: ensaios de sociologia do trabalho. Bauru: Canal 6, 2013.

ANTUNES, Ricardo. Adeus ao trabalho? Ensaio sobre as metamorfoses e a centralidade do mundo do trabalho. 16. ed. São Paulo: Cortez, 2015.

APPAY, Béatrice e THÉBAUD-MONY, Annie. Précarization sociale, travail et santé. Paris: IRESCO, 1997.

BARBOSA, Alexandre de Freitas. A formação do mercado de trabalho no Brasil. São Paulo. Alameda, 2008.

BOURDIEU, Pierre. A precariedade está hoje por toda a parte. IN: BOURDIEU, Pierre. Contrafogos: táticas para enfrentar a invasão neoliberal. Lucy Magalhães (Trad.). Rio de Janeiro: Jorge Zahar, 1998.

CACCIAMALI, M.C. Um estudo sobre o setor informal urbano e formas de participação na produção. 1982. 163f. Tese (Doutorado em Economia) - Universidade de São Paulo, São Paulo, 1982.

CASTEL, Robert. Metamorfoses da questão social. Uma crônica do salário. Petrópolis: Vozes, 1998.

CARDOSO, Adalberto. A construção da sociedade do trabalho no Brasil: uma investigação sobre a persistência secular das desigualdades. Rio de Janeiro: FGV, 2010.

CESIT. GT Reforma Trabalhista (CESIT/IE/UNICAMP). Dossiê Reforma Trabalhista (em construção). Campinas: Instituto de Economia, 2017.

BRASIL. CONGRESSO. CÂMARA DOS DEPUTADOS. Projeto de Lei $\mathbf{N}^{\mathbf{0}}$ 6787/16. Brasília 2017.

http://www.camara.gov.br/proposicoesWeb/fichadetramitacao?idProposicao=2122076. Acesso em: 14 jun. 2017.

DRUCK, Graça. Precarização e informalidade: alguma especificidade do caso brasileiro. IN: OLIVEIRA, Roberto Véras de; GOMES, Darcilente; TARGINO, Ivan (Orgs.). Marchas e contramarchas da informalidade do trabalho: das origens às novas abordagens. João Pessoa: Editora Universitária, 2011.

. Trabalho, precarização e resistências: novos e velhos desafios? IN: Caderno CRH, Salvador, v.24, n.1, p. 37587, 2011 b.

GARCIA, Afrânio. A sociologia rural no Brasil: entre escravos do passado e parceiros do futuro. IN: Sociologias, Porto Alegre, ano 5, n. 10, jul/dez, 154-189 p., 2003. 
IBGE. Pesquisa nacional por amostra de domicílios contínua. Trimestral. Brasília: IBGE, 2018. Disponível https://ww2.ibge.gov.br/home/estatistica/indicadores/trabalhoerendimento/pnad_continua/. Acesso: 13 out. 2018.

KREIN, José Dari. O desmonte dos direitos, as novas configurações do trabalho e o esvaziamento da ação coletiva: consequências da reforma trabalhista. IN: Tempo Social, Revista de Sociologia da USP, v. 30, 2018.

KREIN et al. Flexibilização das relações de trabalho: insegurança para os trabalhadores. IN: KREIN et al (Org.). Dimensões críticas da reforma trabalhista no Brasil. José Dari Krein, Denis Maracci Gimenez, Anselmo Luis dos Santos (Org.). Campinas: Curt Nimuendajú, 2018.

MACHADO DA SILVA, Luis. Mercado metropolitano de trabalho manual e marginalidade. 1971. Dissertação (Mestrado em Antropologia Social) - Universidade Federal do Rio de Janeiro, Rio de Janeiro, 1971.

MANZANO, Marcelo e Caldeira, Christian Duarte. Dinâmica recente do mercado de trabalho brasileiro ainda nos marcos da CLT. IN: KREIN et al (Org.). Dimensões críticas da reforma trabalhista no Brasil. KREIN, José Dari; GIMENEZ, Denis Maracci; SANTOS, Anselmo Luís dos (Org.). Campinas: Curt Nimuendajú, 2018.

MARINHO, Rogério. Relatório da comissão especial destinada a proferir parecer ao projeto de lei $\mathbf{n}^{\mathbf{0}}$ 6.787, de 2016, abril de 2017. Substitutivo ao projeto de lei no 6.787, de 2016, abril de 2017. Disponível em: http://www.camara.gov.br/proposicoesWeb/fichadetramitacao?idProposicao=2129284. Acesso em: 12 jun. 2017.

MTE. Cadastro geral de empregados e desempregados. Ministério do Trabalho e emprego. Brasília. Disponível em: http://pdet.mte.gov.br/acesso-online-as-bases-de-dados. Acesso em: 10 out. 2018 .

OLIVEIRA, F. de. Crítica à razão dualista: o ornitorrinco. São Paulo: Boitempo, 2003.

PASTORE, José. Reforma trabalhista o que representa para o Brasil. IN: O Globo. São Paulo, 18 de Abril de 2017. Disponível em: http://www.josepastore.com.br/artigos/rt/rt_385.htm. Acesso em: 29 jun. 2017.

Relações do Trabalho. Salvador, 08 jun. 2006. Disponível em:
http://www.josepastore.com.br/artigos/rt/rt_152.htm. Acesso em: 29 jun. 2017.

SANTOS, Anselmo Luís dos; GIMENEZ, Denis Maracci. Desenvolvimento, competitividade e a reforma trabalhista. IN: KREIN et al (Org.). Dimensões críticas da reforma trabalhista no Brasil. KREIN, José Dari; GIMENEZ, Denis Maracci; SANTOS, Anselmo Luis dos. Campinas: Curt Nimuendajú, 2018.

SOUZA, Jessé. A elite do atraso: da escravidão à Lava Jato. Rio de Janeiro: Leya, 2017.

SENNETT, Richard. A corrosão do caráter: impactos pessoais no capitalismo contemporâneo. São Paulo: Record, 1999. 
THEBAUD-MONY, Annie; DRUCK, Graça. A corrosão dos direitos dos trabalhadores na França e no Brasil. IN: DRUCK, Graça; FRANCO, Tânia Franco (Org.) A perda da razão social do trabalho: terceirização e precarização. São Paulo: Boitempo, 2007.

\section{AUTOR:}

\section{José Aderivaldo Silva da Nóbrega}

Professor efetivo de Sociologia no Ensino Médio Regular da rede pública da Paraíba. Membro do grupo de Pesquisa Trabalho, Desenvolvimento e Políticas Públicas (TDEPP/UFCG)

E-mail: aderivaldocg@gmail.com

Recebido em 10/07/2019.

Aceito em 18/11/2019. 